\title{
In situ synthesis of epoxy nanocomposites with hierarchical surface-modified $\mathrm{SiO}_{2}$ clusters
}

\author{
Mohammed Mostafa Adnan ${ }^{1} \cdot$ Erlend Grytli Tveten $^{2} \cdot$ Rany Miranti $^{1} \cdot$ Sverre Hvidsten $^{2} \cdot$ Marit-Helen Glomm Ese $^{2}$. \\ Julia Glaum ${ }^{1} \cdot$ Mari-Ann Einarsrud $\mathbb{D}^{1}$
}

Received: 3 October 2019 / Accepted: 7 January 2020 / Published online: 30 January 2020

(c) The Author(s) 2020

\begin{abstract}
Polymer nanocomposites are often produced using in situ approaches where an inorganic filler (as the dispersed phase) is synthesized directly in an organic matrix. Such an approach generally leads to improved dispersion and reduced agglomeration of the filler material. Epoxy-based nanocomposites have demonstrated promising properties for application as high-voltage insulation materials. In this work, a sol-gel based method has been adapted to synthesize surface-functionalized $\mathrm{SiO}_{2}$ in situ in epoxy. The synthesized $\mathrm{SiO}_{2}$ moieties were dispersed in clusters of $10-80 \mathrm{~nm}$, and formed chemical bonds with the epoxy monomers via a silane coupling agent. Raman spectra show the formation of four-membered $\mathrm{D}_{1}$ rings, which may be part of a cage-like structure similar to that of polyhedral oligomeric silsesquioxanes (POSS). SAXS measurements indicate that the $\mathrm{SiO}_{2}$ clusters consist of a hierarchical structure with an increasing fractal dimension with increasing $\mathrm{SiO}_{2}$ content. The nanocomposites displayed improved thermal stability, while the glass transition behavior varied depending on the structure and content of the $\mathrm{SiO}_{2}$ moieties. While the relative permittivity showed no significant changes from that of pure epoxy, the onset of the dielectric relaxation changed with the $\mathrm{SiO}_{2}$ structure and content, similar to the behavior observed for the glass transition.
\end{abstract}

\section{Graphical Abstract}

The synthesis of surface-functionalized $\mathrm{SiO}_{2}$ in situ in an epoxy resin (DGEBA) resulted in a good dispersion and limited agglomeration of the $\mathrm{SiO}_{2}$ in the nanocomposite, with little deviation in the dielectric properties (i.e., complex permittivity). The $\mathrm{SiO}_{2}$ is suspected to have a hierarchical structure based on the SAXS measurements, with the primary structural level consisting of POSS-like cages, and an evolution in the structure from inorganic chains to cross-linked clusters with increasing $\mathrm{SiO}_{2}$ content.

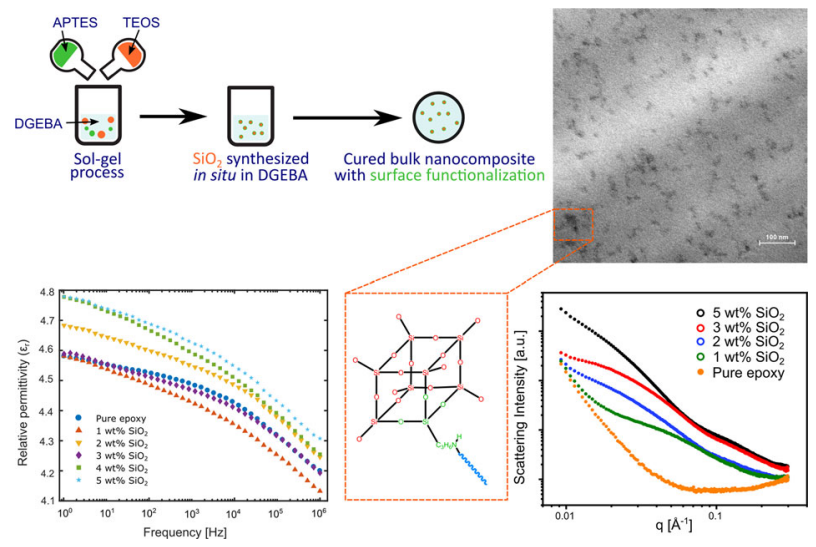

Mari-Ann Einarsrud

mari-ann.einarsrud@ntnu.no

1 Department of Materials Science and Engineering, NTNU
Norwegian University of Science and Technology, Trondheim, Norway

2 SINTEF Energy Research AS, Trondheim, Norway 
Keywords $\mathrm{Sol}-\mathrm{gel} \cdot \mathrm{Nanocomposites} \cdot$ Epoxy $\cdot$ Silica $\cdot$ Dielectric properties

\section{Highlights}

- Surface-modified $\mathrm{SiO}_{2}$ clusters of 10-80 nm synthesized in situ in epoxy using a sol-gel method.

- Raman spectra show the formation of four-membered $\mathrm{SiO}$ rings $\left(\mathrm{D}_{1}\right.$ breathing mode).

- SAXS indicates the presence of a hierarchical structure within the $\mathrm{SiO}_{2}$ clusters.

- The glass transition and the dielectric relaxation varies with the structure and content of $\mathrm{SiO}_{2}$.

- No significant changes in relative permittivity.

\section{Introduction}

Epoxy-based nanocomposites, containing inorganic oxide nanoparticles as filler, are often used as nanodielectrics in high-voltage insulation materials or microelectromechanical systems due to the novel properties exhibited by these hybrid materials [1-3]. Several studies have presented the advantages of adding nanoparticles of $\mathrm{SiO}_{2}, \mathrm{TiO}_{2}, \mathrm{MgO}$, $\mathrm{ZnO}, \mathrm{BN}$, etc. to the epoxy matrix, such as higher dielectric breakdown strengths, reduced complex permittivity, decreased accumulation of space charge, greater mechanical strength and fracture toughness, increased thermal stability, and higher glass transition temperatures [4-11]. However, there is a large spread in the reported results, likely due to the difficulty in consistently achieving a homogeneous and stable dispersion of nanoparticles in epoxy. A poor dispersion quality can result in a deterioration of the desired dielectric properties [12]. The use of surface modifiers for the nanoparticles, such as silane coupling agents (SCAs) or organophosphate ligands, have been shown to improve the properties of epoxy nanocomposites [13]. These surface modifiers allow chemical bonds to form at the interfaces between the nanoparticles and the polymer chains, facilitating the dispersion of the nanoparticles [14], thereby increasing the interfacial area. The interfacial region between the nanoparticles and the polymer chains is thought to play a key role in determining the properties of these nanocomposites. Tanaka et al. [15] proposed a multicore model to describe the interfacial region, suggesting three distinct layers around the nanoparticles. The strength of the bonds between the polymer chains and the nanoparticle surface varied in each layer, thus affecting the mobility and chain conformation. Earlier studies of the dielectric properties of epoxy nanocomposites have primarily applied an ex situ blending method in the preparation of the materials, which involves mechanically mixing presynthesized nanoparticles into the uncured epoxy resin. The high viscosity of the epoxy resin makes it difficult to disperse the nanoparticles during a physical mixing procedure, which also does not always break up any existing agglomerates. The use of ultrasonication has shown to improve the dispersion quality to a certain degree [16]. However, even with the use of surface-functionalized nanoparticles, the use of ex situ techniques makes it challenging to obtain a homogeneous dispersion of nonagglomerated nanoparticles in the epoxy.

An alternative approach to improve the dispersion quality is in situ synthesis of the inorganic oxide directly in the epoxy using the sol-gel method [17]. One of the advantages of this method is the ability to control the size and morphology of the inorganic moieties formed by adjusting the synthesis parameters, e.g., precursor concentration, temperature, $\mathrm{pH}$, as well as type and amount of catalyst [18]. SCAs may also be applied to form stronger interactions between the organic and inorganic components, resulting in the formation of class II hybrid materials [19]. Several studies have investigated the in situ formation of $\mathrm{SiO}_{2}$ networks in epoxy using sol-gel methods and the resulting changes in the structure, as well as the mechanical and thermal properties of the hybrid materials. Matějka et al. [20,21] showed variations in the fractal dimension of the $\mathrm{SiO}_{2}$ structures formed, depending on whether a singlestep procedure or a two-step procedure (with prehydrolyzed tetraethylorthosilicate (TEOS) as the $\mathrm{SiO}_{2}$ precursor) was used in the synthesis. Nazir et al. [22] and Afzal and Siddiqi [18] reported improvements in the dispersion quality, the storage modulus, and a higher glass transition temperature $\left(T_{\mathrm{g}}\right)$ when a two-step procedure with SCAs was used. $\mathrm{Yu}$ et al. [23] found an improved dispersion quality and higher flexural moduli and impact strengths for in situ prepared nanocomposites. However, to the best of our knowledge, no studies have reported the dielectric properties such as the complex permittivity and dielectric breakdown strength of epoxy- $\mathrm{SiO}_{2}$ nanocomposites synthesized using an in situ sol-gel method. These are critical properties for applications of these hybrid materials, for example as nanodielectrics in high-voltage power insulation systems and components.

Hence, the objective of this work is to develop a synthesis route to epoxy- $\mathrm{SiO}_{2}$ nanocomposites with a homogeneous dispersion of the $\mathrm{SiO}_{2}$, by nucleating surfacefunctionalized $\mathrm{SiO}_{2}$ nanoparticles in situ in silanized epoxy. The structure of the hybrid materials and their thermal stability, glass transition, and complex permittivity have been investigated and an improved understanding of the structure-property relations has been developed. This 
provides a solid basis for optimization of the synthesis route to tailor the functional properties of nanocomposites, and eventually improve the dielectric properties.

\section{Experimental}

\subsection{Materials}

Diglycidyl ether of bisphenol-A (DGEBA, molar mass of $340.41 \mathrm{~g} \mathrm{~mol}^{-1}$, epoxide equivalent weight of $170.2 \mathrm{~g} / \mathrm{eq}$ epoxy) was used as the epoxy monomer. Poly(propylene glycol) bis(2-aminopropyl ether) (molar mass of $230 \mathrm{~g} \mathrm{~mol}^{-1}$, and amine-hydrogen equivalent weight of $57.5 \mathrm{~g} / \mathrm{eq}$ amine) was the curing agent for the system. TEOS was used as the precursor for the $\mathrm{SiO}_{2}$, and 3-(aminopropyl) triethoxysilane (APTES) was employed as the coupling agent between the $\mathrm{SiO}_{2}$ and the epoxy chains. Distilled water, brought to $\mathrm{pH} 2$ using concentrated $\mathrm{HCl}(37 \%)$, was the catalyst for the hydrolysis reaction. All chemicals were obtained from Merck.

\subsection{Preparation of samples}

\subsubsection{Pure epoxy samples}

As a reference, samples of pure epoxy (containing no $\mathrm{SiO}_{2}$ or APTES) were prepared by mixing DGEBA with the curing agent (1:1 ratio of epoxide to amine-hydrogen groups) in a beaker for $15 \mathrm{~min}$ at room temperature using a mechanical stirrer. The mixture was degassed in vacuum ( $<10$ mbar pressure) for 15-20 min to remove entrapped gas and air bubbles introduced during the stirring. Two different types of samples were prepared for different characterization methods. Bulk samples $(30 \mathrm{~mm}$ diameter, thickness varying between 3 and $15 \mathrm{~mm}$ ) were formed by pouring the resins into cylindrical Teflon molds. The walls of the molds were waxed lightly with high-vacuum silicone grease to allow the samples to be more easily ejected from the molds after curing. The samples were cured at $100^{\circ} \mathrm{C}$ for $5 \mathrm{~h}$. Thin disc-shaped samples $(10 \mathrm{~cm}$ in diameter, $0.5 \mathrm{~mm}$ thick) were also prepared by mixing the resin and curing agent, and then injecting the resin using $700 \mathrm{mbar}$ of air pressure into a stainless steel mold under vacuum. Frekote NC-150 (Henkel) was used as the release agent for this mold. The mold was then kept under vacuum ( $<10$ mbar pressure) for $30 \mathrm{~min}$ to remove any air bubbles remaining in the resin before curing at $100^{\circ} \mathrm{C}$ for $5 \mathrm{~h}$.

\subsubsection{Epoxy-SiO ${ }_{2}$ nanocomposites}

The chronological two-step procedure employed by Afzal and Siddiqi [18] is adapted in this study for the preparation of the nanocomposite samples. Table 1 shows the reactants and amounts used in the synthesis of the materials with different $\mathrm{SiO}_{2}$ contents. The sample names in Table 1 are used to identify the different materials investigated in this work.

DGEBA was initially heated to $80^{\circ} \mathrm{C}$ under reflux in a round-bottomed flask on a heating mantle to reduce the viscosity and enable easier stirring. APTES was added to the DGEBA (in a weight ratio of 1:10 for APTES:DGEBA) and mixed with a magnetic stirrer for $1 \mathrm{~h}$ at $80^{\circ} \mathrm{C}$. Afterward TEOS was added to the mixture, which was stirred for another hour at $60{ }^{\circ} \mathrm{C}$. The amount of TEOS was varied corresponding to $\mathrm{SiO}_{2}$ content between 0 and $5 \mathrm{wt} \%$ of the total mass. Water (in the ratio 2:1 for water to TEOS and 1.5:1 for water to APTES), brought to $\mathrm{pH} 2$ using concentrated $\mathrm{HCl}$, was then added to catalyze the hydrolysis of TEOS. The mixture was stirred for $4 \mathrm{~h}$ at $60^{\circ} \mathrm{C}$, and then $1 \mathrm{~h}$ at $80^{\circ} \mathrm{C}$ to allow the hydrolysis and condensation reactions to be completed. The mixture was then poured into a beaker, and stirred for $15-18 \mathrm{~h}$ at $80^{\circ} \mathrm{C}$ overnight to evaporate any unreacted water or alcohol byproducts. The resin was then mixed with the curing agent, casted in the molds, and cured using the same procedures as described above. All the samples are identified based on the $\mathrm{SiO}_{2}$ content that originated from the TEOS added. Figure 1 displays a flow chart for the preparation of the nanocomposites.

\subsection{Characterization}

Fourier transform infrared (FTIR) spectroscopy was performed on the thin disc samples using a Bruker Vertex $80 \mathrm{v}$ spectrophotometer equipped with a Bruker Platinum attenuated total reflectance (ATR) diamond. For each sample, 32 scans were recorded at a resolution of $1 \mathrm{~cm}^{-1}$. For the in situ measurements, a drop of the reactant mixture from
Table 1 Compositions of the reactants used in the synthesis of epoxy nanocomposites with varying $\mathrm{SiO}_{2}$ content

\begin{tabular}{lllllll}
\hline Sample name & Epoxy $(\mathrm{g})$ & APTES $(\mathrm{g})$ & TEOS $(\mathrm{g})$ & Water $(\mathrm{g})$ & Curing agent $(\mathrm{g})$ & $\begin{array}{l}\text { Nominal amount of } \mathrm{SiO}_{2} \text { formed } \\
\text { from TEOS }(\mathrm{wt} \%)\end{array}$ \\
\hline EAS0 & 30 & 0 & 0 & 0 & 10.13 & 0 \\
EAS1 & 3 & 1.51 & 0.63 & & 1 \\
EAS2 & & 3.06 & 0.89 & & 2 \\
EAS3 & & 4.63 & 1.17 & 3 \\
EAS4 & & 6.24 & 1.44 & & 4 \\
EAS5 & & 7.88 & 1.73 & & 5 \\
\hline
\end{tabular}


each synthesis step was placed on the ATR diamond. For the measurements on the cured samples, $0.5 \mathrm{~mm}$ films were pressed down on top of the diamond.

Raman spectroscopy was also performed on the disc samples using a WITec Alpha 300R using a monochromatic diode laser $(\lambda=532 \mathrm{~nm})$ at $10 \mathrm{~mW}$ power. The spectra were measured with three accumulations collected over an integration time of $60 \mathrm{~s}$ for each accumulation.

Small angle X-ray scattering (SAXS) measurements were performed on a Bruker NanoSTAR instrument with a $\mathrm{Cu}$ microsource and Våntex-2000 detector, operating at $50 \mathrm{kV}$ and $600 \mu \mathrm{A}$. Both the disc and the bulk samples, which were cut to $1 \mathrm{~mm}$ thickness using a diamond saw, were used. The scattering vector $(q)$ range was from 0.009 to $0.3 \AA^{-1}$, and a glassy carbon standard was used to obtain an absolute scale for the scattering intensities. All the intensities were corrected for the scattering from the empty sample compartment. The measurements were analyzed using both model-independent methods (Guinier and Porod laws), and the unified exponential/power-law fitting model developed by Beaucage (for hierarchical structures) [24] to characterize the inorganic structures after subtraction of the background scattering from the pure epoxy matrix. The software SasView 4.2.0 was used to obtain the fits to the unified model.

Transmission electron microscopy (TEM) was performed using a JEOL JEM $2100 \mathrm{~F}$ with an accelerating voltage of $200 \mathrm{kV}$. The samples were prepared from the bulk samples using an ultramicrotome to cut $\sim 50-100 \mathrm{~nm}$ thin slices.

Differential scanning calorimetry (DSC) was performed on a Netzsch DSC 214 Polyma instrument. Five to ten milligrams sized pieces were cut from the bulk samples and used for the measurements. The samples were cycled four times between 0 and $200{ }^{\circ} \mathrm{C}$ at $10{ }^{\circ} \mathrm{C} / \mathrm{min}$ rates (both heating and cooling), with $\mathrm{N}_{2}$ gas flow at $40 \mathrm{~mL} / \mathrm{min}$. The glass transition temperature was determined from the local maxima in the heat capacity measured in the final cycle. Thermogravimetric analysis (TGA) was carried out on a Netzsch STA 449C using an alumina crucible and synthetic air ( $30 \mathrm{~mL} / \mathrm{min}$ gas flow). The samples were first held at $120^{\circ} \mathrm{C}$ for $30 \mathrm{~min}$, before being heated to $900{ }^{\circ} \mathrm{C}$ at $10^{\circ} \mathrm{C} / \mathrm{min}$.

Dielectric spectroscopy was performed using a Novocontrol Spectrometer with an Alpha Beta dielectric analyzer and a BDS1200 sample cell. The cylindrical bulk samples were grinded with $\mathrm{SiC}$ paper (\#800, \#1200, and \#2000 grade) and dried in a vacuum oven at $120^{\circ} \mathrm{C}$ for $2 \mathrm{~h}$, before gold electrodes were sputtered onto the top and bottom surfaces. An electric field of $0.1 \mathrm{~V} / \mathrm{mm}$ was used, and the spectroscopy was performed between 1 and $10^{6} \mathrm{~Hz}$ at room temperature. Measurements were performed on four to five samples for each nanocomposite with $\mathrm{SiO}_{2}$ and for pure epoxy.

\section{Results}

\subsection{Structure and morphology of the nanocomposites}

The prepared nanocomposite and pure epoxy samples were transparent and clear. No visual indication of phase separation of the inorganic filler from the epoxy matrix was observed. The dispersion of the in situ prepared $\mathrm{SiO}_{2}$ nanoparticles was observed from the representative TEM and STEM images in Fig. 2. The $\mathrm{SiO}_{2}$ nanoparticles are arranged in irregularly shaped clusters varying in size

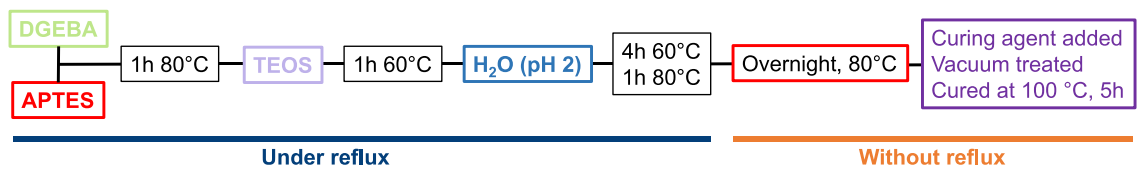

Fig. 1 Flow chart outlining the synthesis procedure for the preparation of nanocomposites

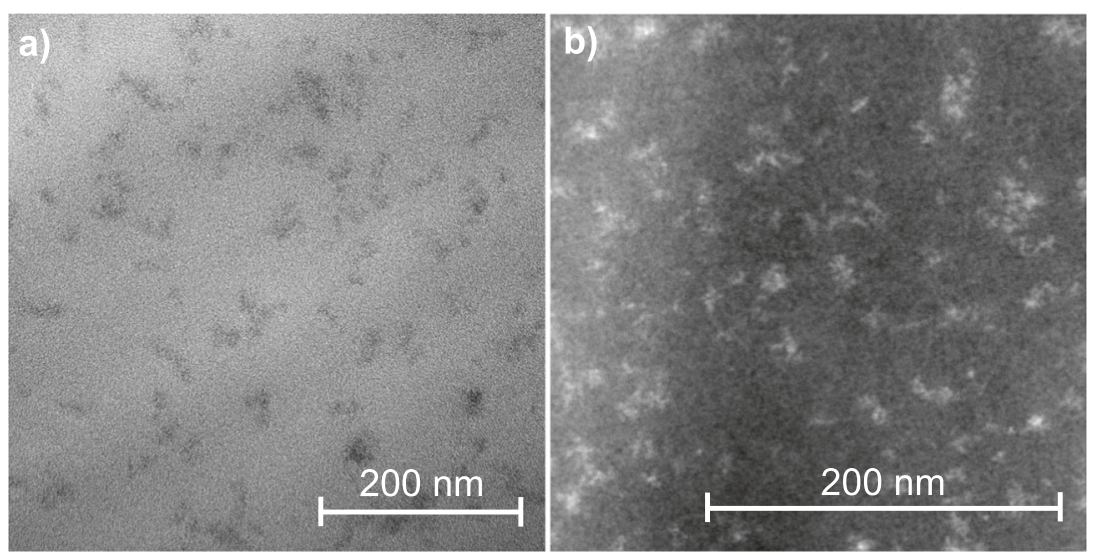

Fig. 2 a TEM image of the nanocomposite EAS5, and b STEM dark-field image of the nanocomposite EAS2 
between 10 and $20 \mathrm{~nm}$ for the EAS2 sample, and between 20 and $50 \mathrm{~nm}$ with some larger clusters up to $80 \mathrm{~nm}$ for the EAS5 sample.

Figure $3 \mathrm{a}$ shows the development of the FTIR spectra during the in situ synthesis. Figure $3 b$, c magnify the regions in which important changes occur as the reaction proceeds. The strong characteristic bands from $\mathrm{Si}-\mathrm{O}-\mathrm{C}$ bonds $\left(1070-1105 \mathrm{~cm}^{-1}\right)$ and the ethyl groups $\left(940-970 \mathrm{~cm}^{-1}\right)$, present in both APTES and TEOS, are observed [25]. These bands are strongest upon addition of TEOS, but as the reaction proceeds they become relatively weaker (compared with the band at $1036 \mathrm{~cm}^{-1}$ assigned to the aromatic $\mathrm{C}-\mathrm{O}-\mathrm{C}$ group in the DGEBA [26]). The band originating from the oxirane ring at $915 \mathrm{~cm}^{-1}$ [26] is also weaker upon reaction with APTES (shown by the dotted red lines). The broad band between 3300 and $3600 \mathrm{~cm}^{-1}$ corresponds to $\mathrm{O}-\mathrm{H}$ groups, which becomes stronger at later stages of the reaction. The characteristic band from the $\mathrm{N}-\mathrm{H}$ bonds in APTES at $1620 \mathrm{~cm}^{-1}$ is difficult to distinguish due to overlap with the $\mathrm{C}=\mathrm{C}$ aromatic band in DGEBA [26]. The spectra of the pure epoxy (EAS0) and nanocomposite epoxy film (EAS4) after curing are shown in Fig. 4. The broad band from the $\mathrm{O}-\mathrm{H}$ groups is more intense due to the opening of all the oxirane rings in DGEBA by the curing agent, which results in a significant decrease in the characteristic band at $915 \mathrm{~cm}^{-1}$. The O-Si-O rocking band is observed at $450 \mathrm{~cm}^{-1}$ in the nanocomposite. The more characteristic fingerprint of inorganic $\mathrm{Si}-\mathrm{O}-\mathrm{Si}$ networks is observed at $1080-1100 \mathrm{~cm}^{-1}$ $[27,28]$ for the nanocomposite sample containing $\mathrm{SiO}_{2}$, shown in the inset. The pure epoxy also exhibits a band in the same range, which is attributed to the $\mathrm{C}-\mathrm{O}$ stretching $\left(1089 \mathrm{~cm}^{-1}\right)$ from the curing agent [29]. A considerable
Fig. 3 a FTIR spectra of the reactant mixture during the in situ synthesis at four stages of the reaction process: after the addition of APTES to DGEBA (1), after the addition of TEOS (2), $5 \mathrm{~h}$ after the addition of water (3), and upon completion of the reaction (18 $\mathrm{h}$ without reflux) (4). Magnified spectra are shown in the (b) $800-1200 \mathrm{~cm}^{-1}$ range, and the (c) $2500-3800 \mathrm{~cm}^{-1}$ range as the reaction proceeds

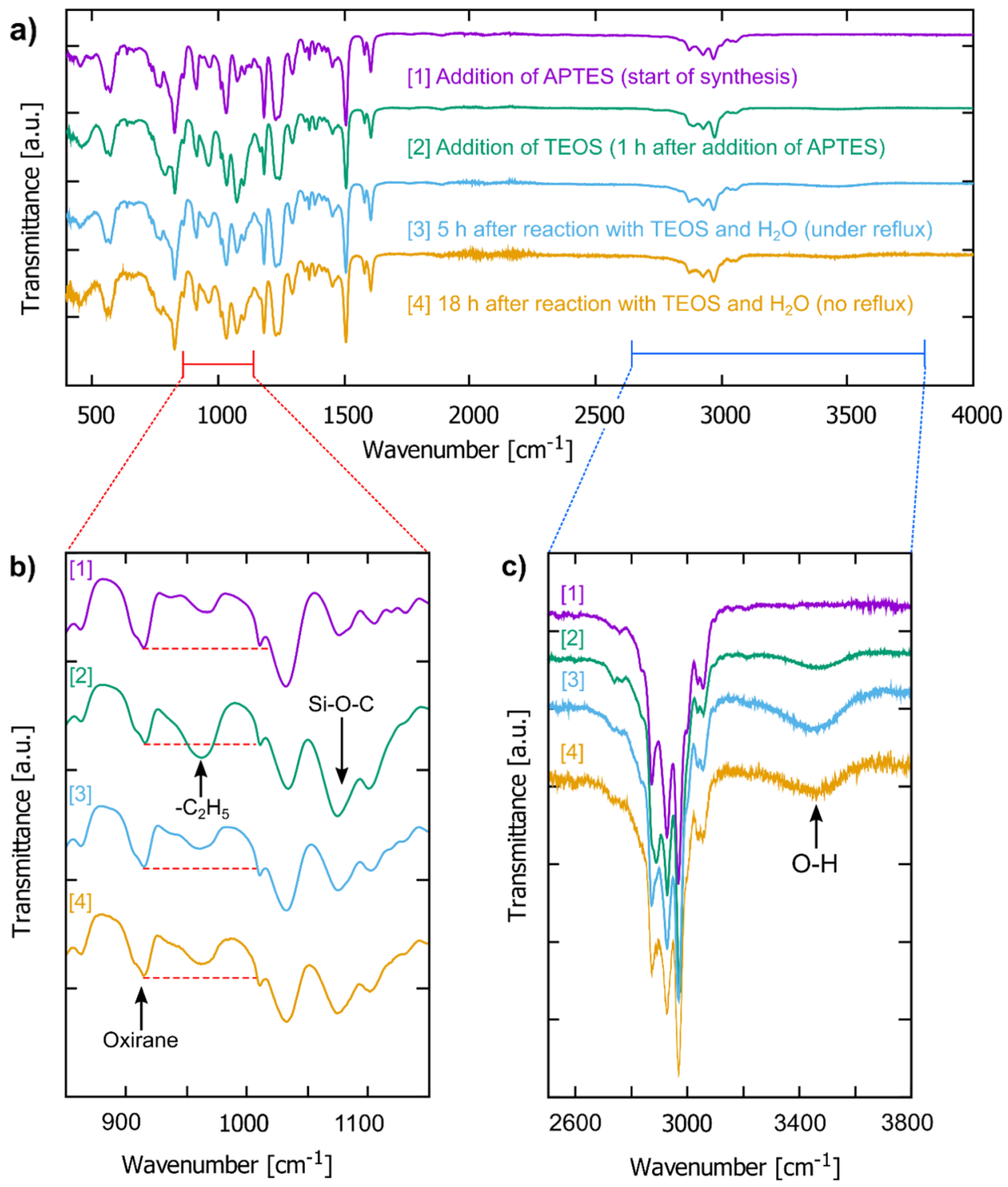


overlap between these two bands is observed in the cured nanocomposite samples containing $\mathrm{SiO}_{2}$.

In the Raman spectra, shown in Fig. 5, the band from the four-membered $\mathrm{SiO}$ rings is observed at $483 \mathrm{~cm}^{-1}\left(\mathrm{D}_{1}{ }^{*}\right)$ in the EAS3 sample. A broad Raman peak in the range of $470-510 \mathrm{~cm}^{-1}$ is detected for samples with a larger $\mathrm{SiO}_{2}$ content (EAS4 and EAS5). This peak can be identified as an overlap of two Raman modes, $\mathrm{D}_{1}{ }^{*}$ mode at $484 \mathrm{~cm}^{-1}$ and $D_{1}$ at $493 \mathrm{~cm}^{-1}$. For pure epoxy (EAS0) these bands are absent in this region, as expected due to the lack of any $\mathrm{SiO}_{2}$, while for small amounts of $\mathrm{SiO}_{2}$ (EAS1 and EAS2) they were weaker and difficult to detect.

Figure 6a displays the SAXS profiles of pure epoxy as well as nanocomposites with varying $\mathrm{SiO}_{2}$ content. The scattering intensity increased with the amount of $\mathrm{SiO}_{2}$. All the materials exhibit a broad knee feature in a $q$ range

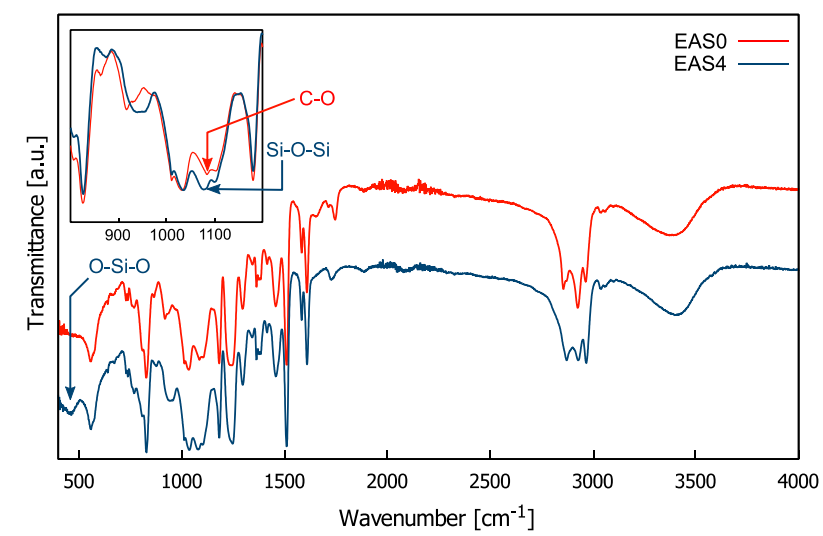

Fig. 4 FTIR spectra of cured films of pure epoxy (EAS0) and epoxy nanocomposite with $\mathrm{SiO} 2$ (EAS4). The inset shows a magnified part of the low frequency region of the spectra, exhibiting the difference in the spectra

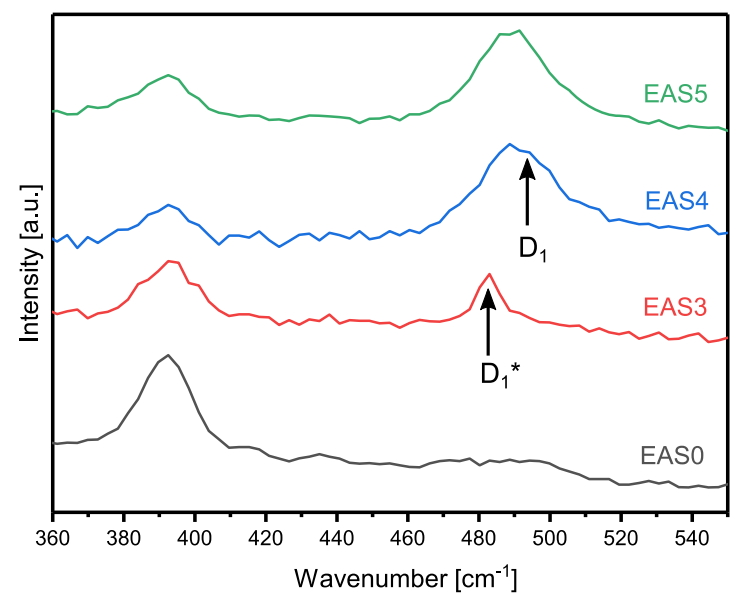

Fig. 5 Raman spectra of pure cured epoxy (EAS0) and epoxy nanocomposites with different $\mathrm{SiO} 2$ contents (EAS3, EAS4, and EAS5). The Raman shift for the different four-membered $\mathrm{SiO}$ rings $\left(\mathrm{D}_{1}\right.$ and $\left.\mathrm{D}_{1} *\right)$ are indicated between 0.02 and $0.07 \AA^{-1}$, which shifts to lower $q$ values with increasing $\mathrm{SiO}_{2}$ content. The nanocomposites with higher $\mathrm{SiO}_{2}$ content (EAS3 and EAS5) possess an additional knee at higher $q$ values (between 0.1 and $0.2 \AA^{-1}$ ) that can be attributed to inorganic domains with higher electron density [30]. These features in the scattering may be attributed to inorganic nanoparticles arranged in hierarchical structures at different size scales [31]. The scattering data for all the samples were analyzed using modelindependent methods. At low $q$ values below $0.02 \AA^{-1}$, Guinier analysis was performed to calculate the radius of gyration, $R_{g}$, for the nanoparticles. Assuming that the scattering objects are spherical, the size of the inorganic domains $(d)$ was calculated using as

$d=2 R_{g} \sqrt{\frac{5}{3}}$.

The slopes of the linear regions of a $\log -\log$ plot $(\log (I)$ vs $\log (q))$ at intermediate $q$ values $(0.03<q<0.13)$, where the best linear fit for each plot could be obtained, were calculated to obtain the power-law scaling of the scattering by the inorganic structures (fractal dimension, $D$ ). Both the model-independent analysis and the fitting to the unified model were performed after subtraction of the background scattering from the pure epoxy matrix, so that the calculations represent the $\mathrm{SiO}_{2}$ only and do not include scattering effects from the epoxy.

The fits of the SAXS data with the unified model [24] using two structural levels for the EAS3 and EAS5 samples in the $q$ range $0.015-025 \AA^{-1}$ are shown in Fig. $6 \mathrm{~b}$. The first structural level was assumed to consist of perfectly spherical nanoparticles (with size $d^{1}$ ), which are then arranged in clusters (of size $d^{2}$ ) to form the second structural level. Acceptable fits were not obtained for the samples containing a lower amount of $\mathrm{SiO}_{2}$, since they do not exhibit the scattering feature at higher $q$. From these fits, the radius of gyration for the two structural levels $\left(R_{g}{ }^{1}\right.$ and $\left.R_{g}{ }^{2}\right)$, the particle size and cluster size ( $d^{1}$ and $d^{2}$, respectively), and the fractal dimension for the clusters in the second structural level $\left(D^{2}\right)$ were obtained. The fractal dimension for the first structural level was fixed to a value of 4 , assuming that the spherical nanoparticles have perfectly smooth surfaces.

Table 2 shows the calculated parameters from the modelindependent Guinier and Porod laws and from the unified model. Using both analysis methods, an increase in the $\mathrm{SiO}_{2}$ content resulted in an increasing $R_{g}$ (and therefore an increasing particle or cluster size) and an increase in the fractal dimension. The increase in $R_{g}$ indicates the formation of larger inorganic domains. The calculated size of these structures is comparable with the sizes observed from the TEM images. The increase in the fractal dimension may also represent an evolution of the network structure of the $\mathrm{SiO}_{2}$ - the samples with a lower $\mathrm{SiO}_{2}$ content (EAS1, 


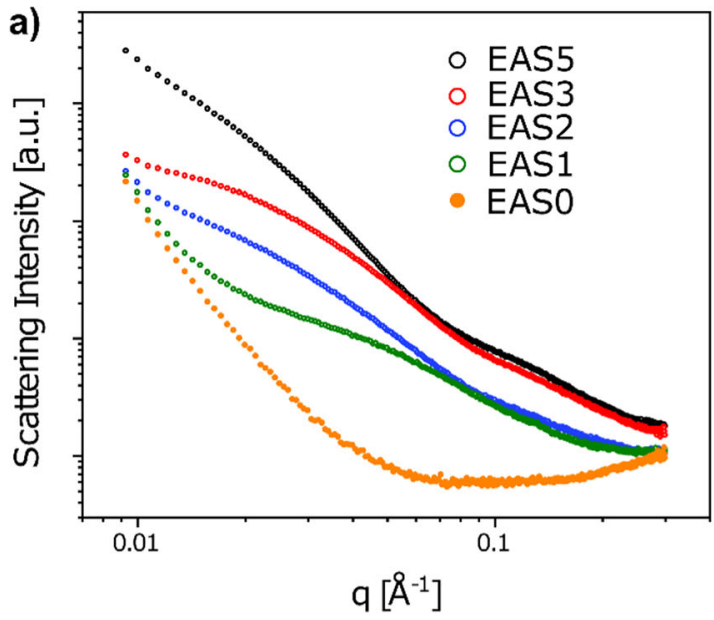

Fig. 6 a SAXS profiles of pure epoxy (EAS0) and epoxy nanocomposites with different $\mathrm{SiO}_{2}$ contents (EAS1, EAS2, EAS3, and EAS5), and $\mathbf{b}$ the unified model fit to the scattering data, as shown by

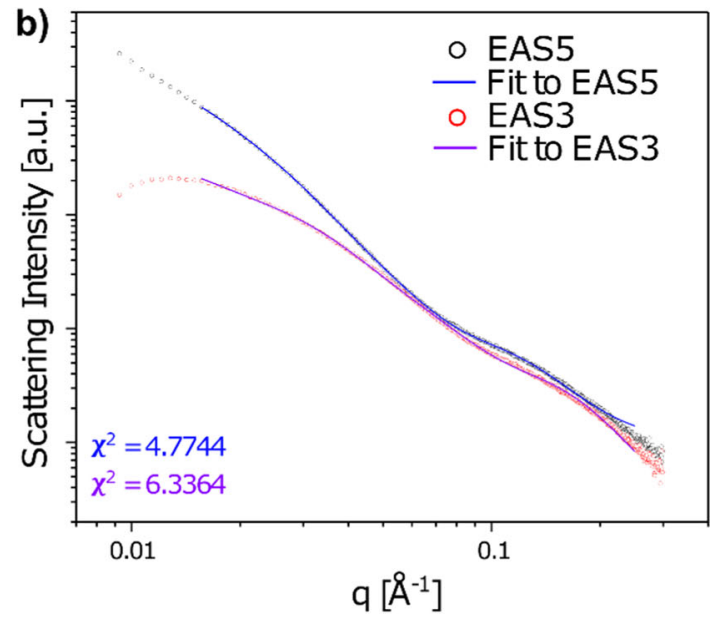

the solid lines, for the EAS3 and EAS5 samples. The reduced $\chi^{2}$ values for the two fits are also shown
Table 2 Calculated structural parameters of the epoxy- $\mathrm{SiO}_{2}$ nanocomposites calculated from the model-independent Guinier and Porod laws, and from the unified model fits

\begin{tabular}{|c|c|c|c|c|c|c|c|c|}
\hline \multirow[t]{2}{*}{ Sample } & \multicolumn{3}{|c|}{ Guinier and Porod laws } & \multicolumn{5}{|c|}{ Unified model } \\
\hline & $R_{g}(\mathrm{~nm})$ & $d(\mathrm{~nm})$ & $D$ & $R_{g}{ }^{1}(\mathrm{~nm})$ & $d^{1}(\mathrm{~nm})$ & $R_{g}^{2}(\mathrm{~nm})$ & $d^{2}(\mathrm{~nm})$ & $D^{2}$ \\
\hline EAS5 & 12 & 31 & 3.06 & 2.8 & 7 & 13 & 34 & 3.48 \\
\hline EAS3 & 6 & 16 & 2.47 & 2.1 & 5 & 11 & 28 & 2.91 \\
\hline EAS2 & 7 & 18 & 2.33 & - & - & - & - & - \\
\hline EAS1 & 4 & 10 & 1.94 & - & - & - & - & - \\
\hline
\end{tabular}

The superscripts 1 and 2 indicate the first and second levels in the hierarchical structures
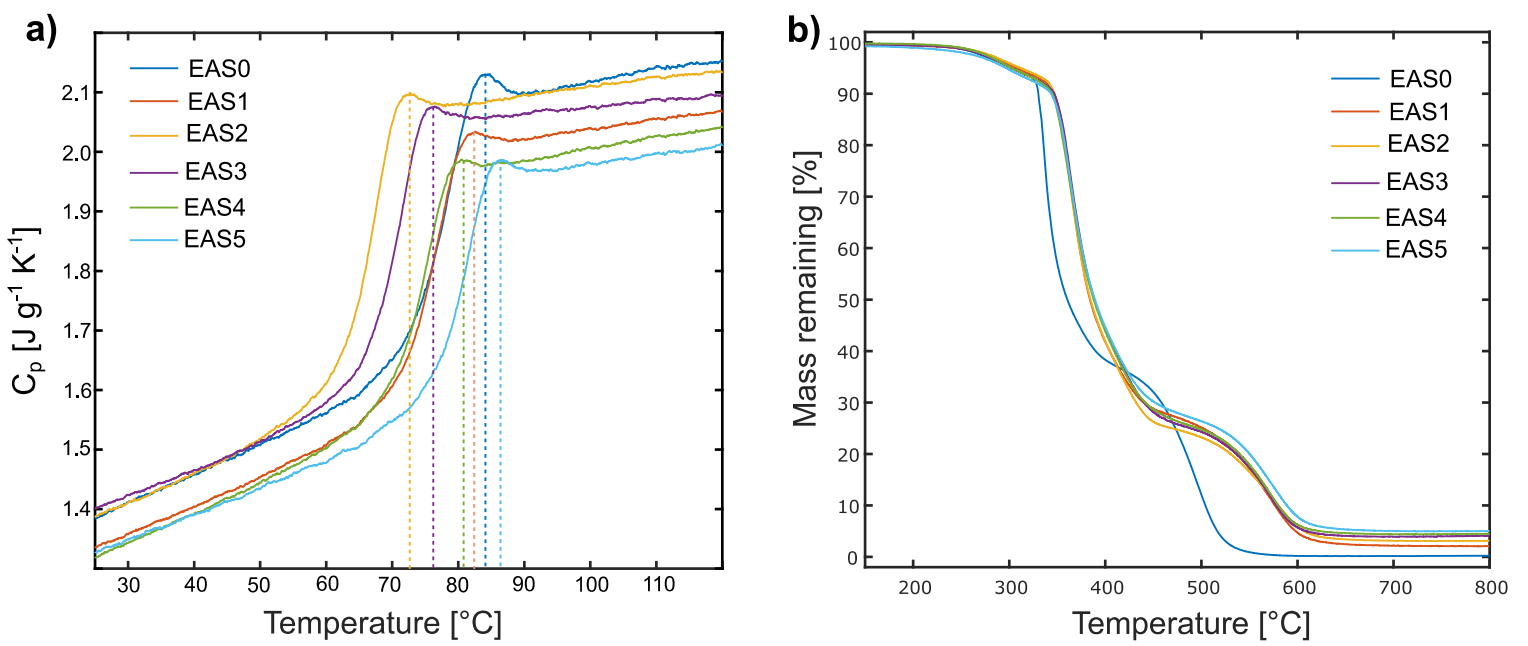

Fig. 7 a Variations in the heat capacity, and $\mathbf{b}$ thermogravimetric analysis of the nanocomposites with different $\mathrm{SiO}_{2}$ contents. The dotted lines indicate the glass transition temperature $\left(T_{\mathrm{g}}\right)$

EAS2, and EAS3) are more likely to consist of inorganic chains, representing a mass fractal structure $(D<3)$, while for a higher $\mathrm{SiO}_{2}$ content (EAS5) the chains are coiled up and cross-linked into a more compact structure, representing a surface fractal $(3<D<4)$.

\subsection{Properties of the nanocomposites}

The glass transition temperatures $\left(T_{\mathrm{g}}\right)$ of the nanocomposites were determined from the local maxima in the heat capacity as shown in Fig. 7a, and the measured values are 
shown in Table 3. The incorporation of $\mathrm{SiO}_{2}$ in epoxy resulted in an initial decrease of $T_{\mathrm{g}}$ to $\sim 73{ }^{\circ} \mathrm{C}$ for $2 \mathrm{wt} \% \mathrm{SiO}_{2}$, followed by an increase to $87{ }^{\circ} \mathrm{C}$ for $5 \mathrm{wt} \% \mathrm{SiO}_{2}$. Figure $7 \mathrm{~b}$ shows the TGA of the nanocomposites, displaying the increased thermal stability of the nanocomposites compared with pure epoxy at temperatures above $325^{\circ} \mathrm{C}$. Above $330^{\circ} \mathrm{C}$, the pure epoxy experiences a rapid drop in mass as it decomposes. The nanocomposites do not degrade until $\sim 350^{\circ} \mathrm{C}$. The pure epoxy is completely decomposed before $600^{\circ} \mathrm{C}$, while in the nanocomposites the decomposition is delayed to $650{ }^{\circ} \mathrm{C}$. The remaining mass beyond $650{ }^{\circ} \mathrm{C}$ corresponds to the amount of $\mathrm{SiO}_{2}$ in the sample. The measured values of the temperatures for the initial decomposition $(10 \%$ mass loss) from the TGA are included in Table 3.

Figure 8 shows the results from the dielectric spectroscopy measurements, i.e., the relative permittivity (or dielectric constant) and the dielectric loss tangent ( $\tan \delta$ ) of pure epoxy and epoxy- $\mathrm{SiO}_{2}$ nanocomposites. The permittivity curves and dielectric loss tangents were averaged over at least four different samples for each composition. The addition of $\mathrm{SiO}_{2}$

Table 3 Thermal and dielectric properties of pure epoxy and epoxy$\mathrm{SiO}_{2}$ nanocomposites

\begin{tabular}{cccccc}
\hline Sample & $T_{\mathrm{g}}\left[{ }^{\circ} \mathrm{C}\right]$ & $T_{10}{ }^{\mathrm{a}}\left[{ }^{\circ} \mathrm{C}\right]$ & Permittivity $^{\mathrm{b}}$ & $\tan \delta^{\mathrm{b}}$ & Relaxation frequency $^{\mathrm{c}}[\mathrm{Hz}]$ \\
\hline EAS0 & 83 & 330 & 4.53 & 0.0049 & 2630 \\
EAS1 & 82 & 347 & 4.50 & 0.0086 & 2874 \\
EAS2 & 73 & 347 & 4.61 & 0.0069 & 11501 \\
EAS3 & 76 & 347 & 4.52 & 0.0067 & 6391 \\
EAS4 & 81 & 343 & 4.68 & 0.0097 & 5648 \\
EAS5 & 86 & 343 & 4.70 & 0.0076 & 4531 \\
\hline
\end{tabular}

${ }^{\mathrm{a}}$ Temperature at which $10 \%$ of mass has thermally decomposed

${ }^{\mathrm{b}}$ Average values measured at $50 \mathrm{~Hz}$

${ }^{c}$ Frequency at the onset of the dielectric relaxation

a)

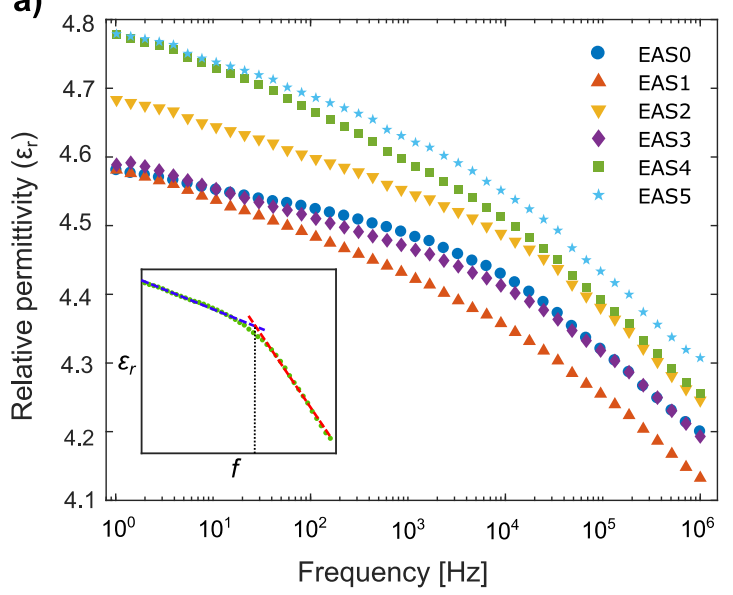

Fig. 8 a Real relative permittivities $(\varepsilon)$, and $\mathbf{b}$ the loss tangent $(\tan \delta$ ) of pure epoxy (EAS0) and epoxy nanocomposites (EAS1, EAS2, EAS3, EAS4, and EAS5) as a function of frequency ( $f$ ). The inset in a demonstrates how the frequency for the start of the dielectric does not significantly affect the complex permittivity. The real relative permittivity differed between 0.2 and 0.4 from the values of pure epoxy across all frequencies measured. The nanocomposites exhibited a larger dielectric loss than the pure epoxy below $500 \mathrm{~Hz}$, although the losses for all the samples were generally quite low (below $1 \%$ ) at $50 \mathrm{~Hz}$.

Table 3 also contains the permittivity and loss tangent $(\tan \delta)$ at $50 \mathrm{~Hz}$ for each material, as well as the frequency for the onset of the dielectric relaxation exhibited by all the materials. This frequency was determined by the intersection of two linear regression lines from the two regions, as demonstrated in the inset in Fig. 8.

\section{Discussion}

\subsection{Reaction pathway and resulting structure of the inorganic component}

A schematic showing the proposed pathway for the reaction, based on the changes observed in the FTIR spectra, is shown in Fig. 9. The decrease in the band from the oxirane ring, the emergence of the $\mathrm{O}-\mathrm{H}$ band, and the absence of the $\mathrm{N}-\mathrm{H}$ band confirm that the DGEBA monomers have been silanized with the APTES. Upon addition of TEOS and the subsequent reaction with water, no further changes are observed in the oxirane ring band. However, the $\mathrm{O}-\mathrm{H}$ band increases over time, which can be attributed to the hydrolysis of the TEOS and subsequent formation of surface $\mathrm{O}-\mathrm{H}$ (silanol) groups after the $\mathrm{SiO}_{2}$ clusters have formed. The band for the $\mathrm{Si}-\mathrm{O}-\mathrm{C}$ groups is present in the initial mixture (due to the APTES) and is seen to increase after addition of TEOS, as expected. The initial decrease in this signal over the first few hours is attributed to the

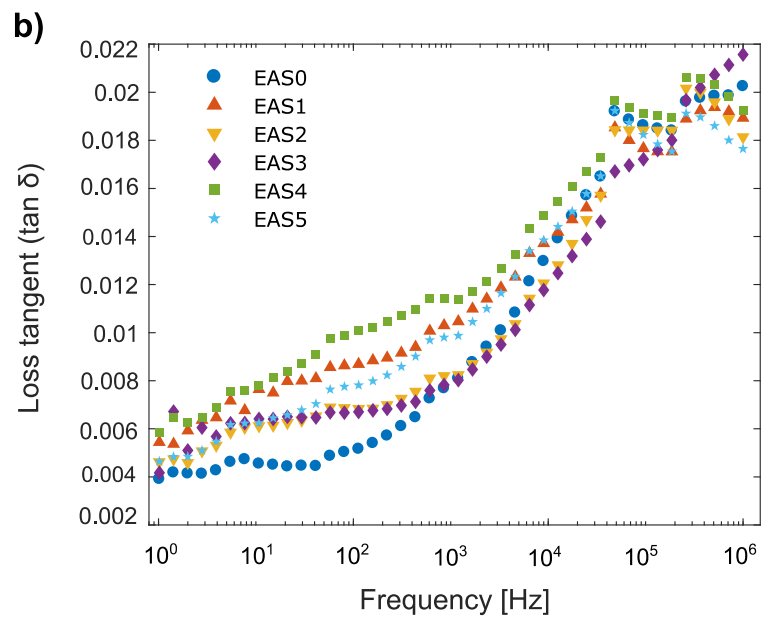

relaxation was determined. The standard deviation in the average permittivity values is $<0.05$ for all the samples, except the EAS3 sample where the standard deviation is 0.25 . The standard deviation in the average $\tan \delta$ values is $<0.003$ 

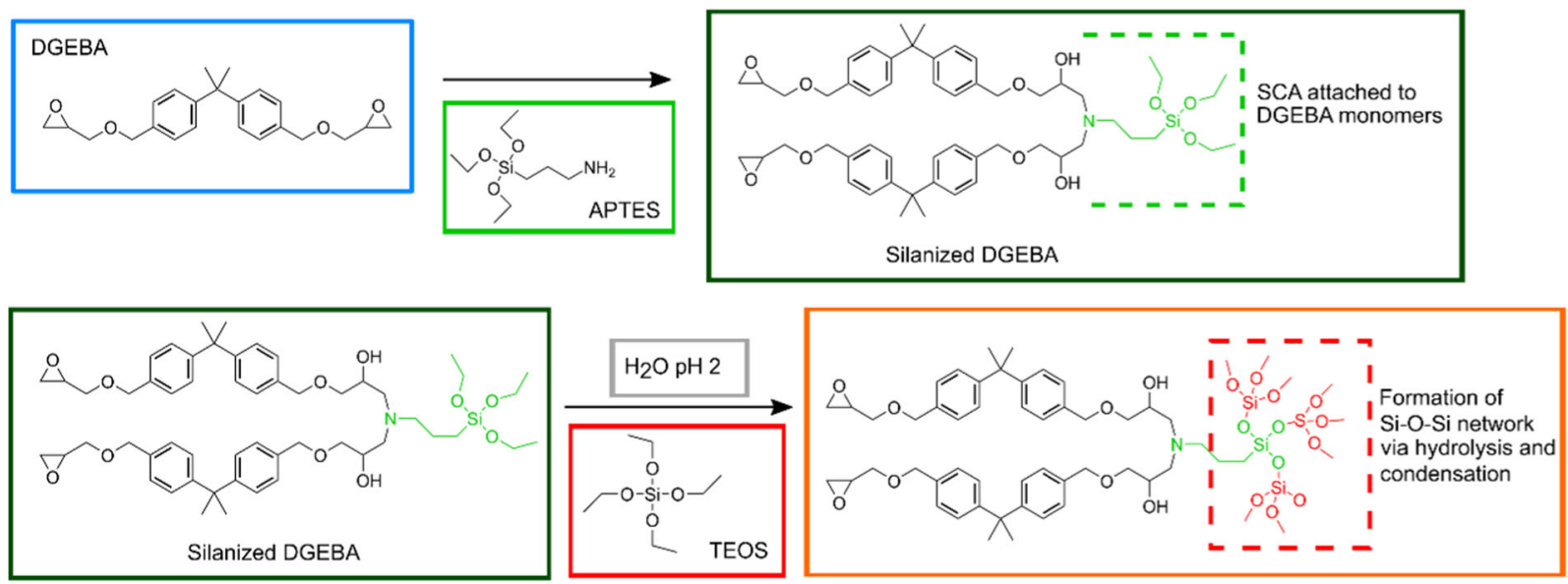

Fig. 9 Schematic of the possible reaction pathway during the in situ synthesis of $\mathrm{SiO}_{2}$ nanoparticles from hydrolysis and condensation of TEOS in the epoxy resin

breaking of the $\mathrm{Si}-\mathrm{O}-\mathrm{C}$ bond during hydrolysis. However, the subsequent formation of $\mathrm{Si}-\mathrm{O}-\mathrm{Si}$ bonds (which are characterized by a band in the same region) by the condensation reactions results in no further changes over the remainder of the reaction.

As seen in the Raman spectra (Fig. 5), the $\mathrm{D}_{1}$ breathing mode at $495 \mathrm{~cm}^{-1}$ is shifting between 484 and $503 \mathrm{~cm}^{-1}$ depending on the organic groups that are attached to the $\mathrm{Si}$ [32]. The shift to $\mathrm{D}_{1}{ }^{*}$ in samples containing $\mathrm{SiO}_{2}$ can therefore be attributed to the surface functionalization, where one of the $\mathrm{Si}$ in the four-membered rings originates from the APTES and is connected to a carbon chain instead of oxygen. Due to the presence of the $\mathrm{D}_{1}$ * mode only for the nanocomposite with $3 \mathrm{wt} \%$ of $\mathrm{SiO}_{2}$, it is likely that all of the $\mathrm{SiO}_{2}$ structures formed are chemically bonded directly to the epoxy, while for higher $\mathrm{SiO}_{2}$ contents (4 and $5 \mathrm{wt} \%$ ) both types of four-membered rings are formed. Therefore, some of these rings are originating from the APTES (as demonstrated in Fig. 9) and the others are formed from the hydrolysis and condensation of isolated TEOS molecules with no covalent attachment to the epoxy.

In addition, the features observed by SAXS of these nanocomposites are similar to those observed for the epoxy nanocomposites containing silsesquioxanes structures $[30,33,34]$. The size of the primary structure level $(5 \mathrm{~nm}$ and $7 \mathrm{~nm}$ for $3 \mathrm{wt} \%$ and $5 \mathrm{wt} \% \mathrm{SiO}_{2}$, respectively) is close to that reported for polyhedral oligomeric silsesquioxanes $(1-3 \mathrm{~nm})[35,36]$. Combined with the observations from Raman, it is therefore likely that the $\mathrm{SiO}_{2}$ domains in the nanocomposites in the present work consist of particles built from oligomeric silsesquioxanes units, consisting of a cage structure with four-membered $\mathrm{SiO}$ rings on each face, as exemplified in Fig. 10. These structures may contain $\mathrm{SiO}$ rings with or without attachment to the APTES (resulting in the $\mathrm{D}_{1} *$ and $\mathrm{D}_{1}$ bands in the Raman spectra).
The model-independent analysis of the SAXS measurements only provides limited information from a certain $q$ range, since Guinier's law is only applied at $q<0.02$. As seen in Fig. 6a, the scattering from the samples shows more complex behavior, particularly for higher $\mathrm{SiO}_{2}$ content, with multiple Guinier regions (represented by the broad features, or knees) separated by a power-law (Porod) region. The data for the samples with 3 and $5 \mathrm{wt} \% \mathrm{SiO}_{2}$ (EAS3 and EAS5) showed a reasonable fit to the unified model developed by Beaucage [24], which describes hierarchical systems that show multiple Guinier and Porod regions in the scattering. These hierarchical systems consist of multiple structure levels, where each structure level is composed by an arrangement of the previous smaller level. The model could not provide good fits for the samples with 1 and $2 \mathrm{wt} \%$ $\mathrm{SiO}_{2}$ (EAS1 and EAS2). The calculated parameters $\left(R_{g}{ }^{2}\right.$ and $d^{2}$ ) for the EAS5 sample are closer to the equivalent parameters calculated using the Guinier and Porod laws $\left(R_{g}\right.$ and $d$ ), while for the EAS3 sample there is a larger difference between them. The unified model also predicts higher fractal dimensions than using Porod's law. However, it should be noted that while the term fractal dimension is used to describe the inorganic structure, it is not necessarily expected that the clusters demonstrate fractal organization over multiple length scales. This is because the fractal dimensions were calculated from the slope in a narrow $q$ range, since the power-law regime displays structural limits due to the Guinier features. However, this is a still useful qualitative descriptor for the type of structure (chains in the case of mass fractals, or a cross-linked network in the case of surface fractals) present in the clusters.

The size of the $\mathrm{SiO}_{2}$ clusters calculated from the SAXS measurements are comparable with those measured by TEM, as seen for the EAS5 sample where the SAXS calculations predict an average cluster size between 31 and 
Fig. 10 Representation of the possible cage-like silsesquioxane structure with four-membered $\mathrm{SiO}$ rings on each face of the cage. The $\mathrm{O}$ atoms attached to the $\mathrm{Si}$ on the corners may be attached to other cages or terminated as surface $\mathrm{O}-\mathrm{H}$ groups a)

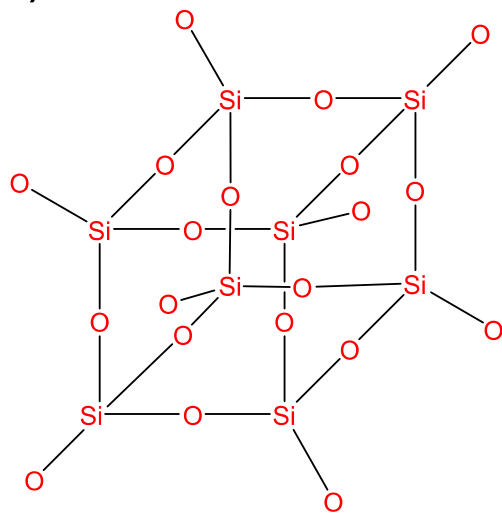

b)

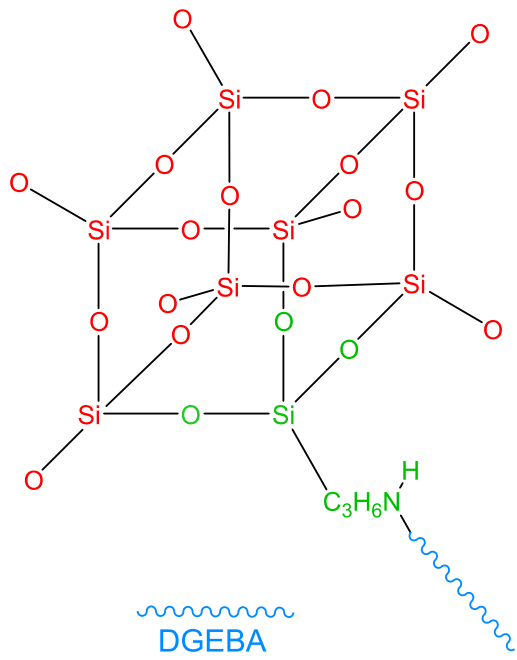

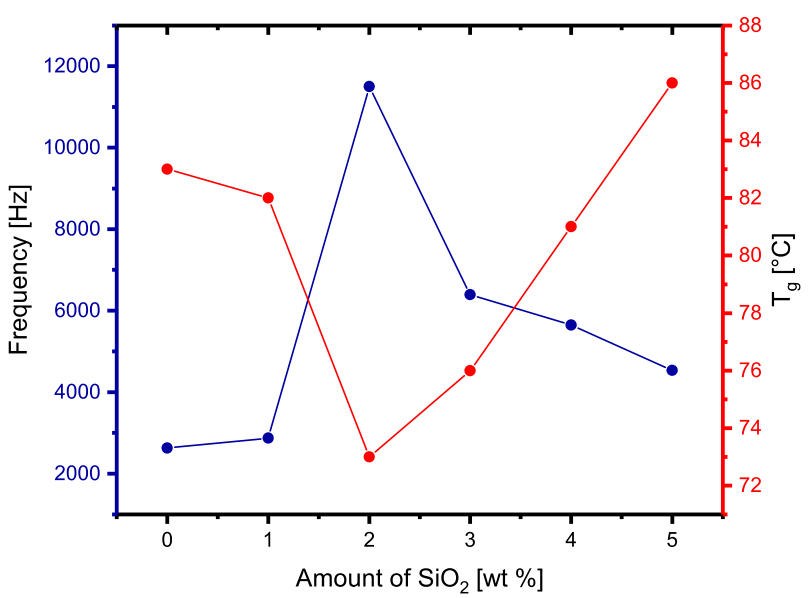

Fig. 11 Comparison of the changes in the glass transition temperature and the dielectric relaxation frequency with the amount of $\mathrm{SiO}_{2}$ in the nanocomposites

$34 \mathrm{~nm}$, and the TEM shows clusters between 20 and $50 \mathrm{~nm}$. A similar comparison can be made for the EAS2 sample. However, it is more difficult to determine from the TEM if the $\mathrm{SiO}_{2}$ is organized as a mass or surface fractal network, as predicted by the SAXS.

\subsection{Properties of the nanocomposites}

The thermal analysis of the nanocomposites displays an interesting effect of the incorporated $\mathrm{SiO}_{2}$ on the glass transition temperature of the epoxy, as shown in Fig. 11. The initial decrease in $T_{\mathrm{g}}$ for lower $\mathrm{SiO}_{2}$ contents may be attributed to the mass fractal structure of the $\mathrm{SiO}_{2}$, with polymer-like chains of silsesquioxanes, exhibiting a plasticizing effect on the surrounding resin [33]. With higher $\mathrm{SiO}_{2}$ content, the inorganic domains form more clustered structures, as evidenced by the increase in fractal dimension from the SAXS measurements. In addition, there are more nanoparticles chemically bonded to the polymer chains for the higher $\mathrm{SiO}_{2}$ content. The nanoparticles and the interfacial regions subsequently become more rigid, hindering the free motion of the polymer chains, thereby leading to an increase in $T_{\mathrm{g}}$. The thermal stability of the materials is also improved by the incorporation of $\mathrm{SiO}_{2}$. The initial degradation temperature is increased by $13-17^{\circ} \mathrm{C}$ compared with pure epoxy, and is independent of the amount of $\mathrm{SiO}_{2}$ added. The plateau in the polymer decomposition was also observed by Bauer et al. [37], and was attributed to char formation where the samples are carbonized. The increased thermal stability of the nanocomposites may be explained by the inorganic nanodomains of $\mathrm{SiO}_{2}$ acting as a barrier to the decay of the organic components, with higher temperatures needed to break the chemical bonds at the interfaces. A closer observation of the morphology of the $\mathrm{SiO}_{2}$ remaining after the pyrolysis of the epoxy shows a skeletal $\mathrm{SiO}_{2}$ network with a shape similar to that of the original sample but slightly smaller in size, suggesting the formation of a continuous inorganic network as the epoxy is burnt off during the degradation.

Another effect of the $\mathrm{SiO}_{2}$ is the shift in the dielectric relaxation observed around $10^{3}-10^{4} \mathrm{~Hz}$ (Fig. 8). This is classified as a $\beta$-relaxation, which is attributed to the relaxations caused by $\mathrm{O}-\mathrm{H}$ groups in the chain $[5,38]$. The onset of the relaxation is observed to shift to a higher frequency initially for samples with a low $\mathrm{SiO}_{2}$ content, or to a lower frequency for samples with a higher $\mathrm{SiO}_{2}$ content, as shown in Table 3 and in Fig. 11. This behavior mimics the changes observed for the $T_{\mathrm{g}}$ in the opposite pattern, and may be explained with a similar reasoning. The samples with 1 and $2 \mathrm{wt} \% \mathrm{SiO}_{2}$ have polymer-like inorganic chains, where the dipoles in the $\mathrm{O}-\mathrm{H}$ groups are more free to move and reorient themselves. These dipoles can therefore keep up 
with the alternating electric field up to higher frequencies, delaying the dielectric relaxation. However, the inorganic domains are more compact and clustered (with higher fractal dimension) in the samples with higher $\mathrm{SiO}_{2}$ content, and the dipoles cannot reorient themselves as quickly. The increased rigidity in the nanodomains results in the dielectric relaxation occurring at lower frequencies.

Tanaka et al. proposed that the presence of inorganic nanofillers possessing strong chemical bonds to the polymer matrix would lead to lower relative permittivity and loss factors [15]. However, despite the dispersion of the in situ grown $\mathrm{SiO}_{2}$ nanodomains, there is no significant influence of the filler content on the permittivity or losses of the materials. Most of the studies reporting a decreased complex permittivity of epoxy nanocomposites have employed spherical nanoparticles that are dispersed. It is therefore possible that the fractal-like network structure of the inorganic nanodomains produced in the present work may be responsible for the absence of any significant changes in the relative permittivity from that of pure epoxy. Thus, it is of interest to vary the parameters of the in situ sol-gel synthesis that are known to affect the reaction kinetics in order to form different nanostructures of the inorganic oxide component.

\section{Conclusion}

The use of an adapted sol-gel method to synthesize and grow $\mathrm{SiO}_{2}$ nanoparticles directly in the epoxy matrix is shown to be a successful approach in obtaining a well dispersed inorganic filler phase in the prepared nanocomposites. The nanoparticles were found to consist of cage-like four-membered $\mathrm{SiO}$ rings, which may then be arranged in fractal-like clusters (either as inorganic chains or a cross-linked network, depending on the $\mathrm{SiO}_{2}$ content). The resulting epoxy- $\mathrm{SiO}_{2}$ nanocomposites have improved thermal stability compared with pure epoxy, while the complex permittivity does not show significant deviation from that of pure epoxy. The presence of $\mathrm{SiO}_{2}$ as more mobile chains causes a softening effect on the surrounding polymer, resulting in a lower glass transition and a delay in the dielectric relaxation. On the other hand, when the $\mathrm{SiO}_{2}$ is present as a cross-linked network, it results in an increased rigidity of the surrounding polymer and an associated increase in the glass transition temperature and earlier onset of the dielectric relaxation. These findings show the influence of the inorganic filler morphology and structure on the properties of the final nanocomposite material.

Acknowledgements The authors would like to acknowledge support from the Research Council of Norway through the Norwegian Center for Transmission Electron Microscopy, NORTEM (197405/F50), and the use of the Norwegian national resource centre for X-ray diffraction and scattering (RECX). The authors would also like to thank Prof. Tor Grande for discussions regarding the thermal analysis, Dr Ragnhild Sæterli for her help in performing the TEM measurements, and Dr Matthias Amman for his help in performing the SAXS measurements. This work benefited from the use of the SasView application, originally developed under NSF award DMR-0520547 (http://www.sasview.org). Open Access funding provided by NTNU Norwegian University of Science and Technology (incl St. Olavs Hospital - Trondheim University Hospital).

Funding This study was funded by The Research Council of Norway through the project "Stipendiatstillinger til SINTEF Energi AS" (project no. 259866).

\section{Compliance with ethical standards}

Conflict of interest The authors declare that they have no conflict of interest.

Publisher's note Springer Nature remains neutral with regard to jurisdictional claims in published maps and institutional affiliations.

Open Access This article is distributed under the terms of the Creative Commons Attribution 4.0 International License (http://crea tivecommons.org/licenses/by/4.0/), which permits unrestricted use, distribution, and reproduction in any medium, provided you give appropriate credit to the original author(s) and the source, provide a link to the Creative Commons license, and indicate if changes were made.

\section{References}

1. Plesa I, Notingher PV, Schlögl S et al. (2016) Properties of polymer composites used in high-voltage applications. Polymers 8:173

2. Tanaka T, Montanari GC, Mulhaupt R (2004) Polymer nanocomposites as dielectrics and electrical insulation-perspectives for processing technologies, material characterization and future applications. IEEE Trans Dielectr Electr Insul 11:763-784

3. Adnan MM, Tveten EG, Glaum J et al. (2019) Epoxy-based nanocomposites for high-voltage insulation: a review. Adv Electron Mater 5:1800505

4. Singha S, Thomas MJ (2008) Dielectric properties of epoxy nanocomposites. IEEE Trans Dielectr Electr Insul 15:12-23

5. Singha S, Thomas MJ (2008) Permittivity and tan delta characteristics of epoxy nanocomposites in the frequency range of 1 MHz-1 GHz. IEEE Trans Dielectr Electr Insul 15:2-11

6. Nelson JK, Fothergill JC (2004) Internal charge behaviour of nanocomposites. Nanotechnology 15:586-595

7. Goyat MS, Rana S, Halder S, Ghosh PK (2018) Facile fabrication of epoxy-TiO2 nanocomposites: a critical analysis of $\mathrm{TiO} 2 \mathrm{impact}$ on mechanical properties and toughening mechanisms. Ultrason Sonochem 40:861-873

8. Kochetov R, Andritsch T, Morshuis PHF, Smit JJ (2012) Anomalous behaviour of the dielectric spectroscopy response of nanocomposites. IEEE Trans Dielectr Electr Insul 19:107-117

9. Andritsch T, Kochetov R, Morshuis PHF, Smit JJ (2010) Short term DC breakdown and complex permittivity of $\mathrm{Al} 2 \mathrm{O} 3$ - and $\mathrm{MgO}$-epoxy nanocomposites. Annu Rep Conf Electr Insul Dielectr Phenom. https://doi.org/10.1109/CEIDP.2010.5723960

10. Mohanty A, Srivastava VK (2013) Dielectric breakdown performance of alumina/epoxy resin nanocomposites under high voltage application. Mater Des 47:711-716

11. Ozsoy I, Demirkol A, Mimaroglu A et al. (2015) The influence of micro- and nano-filler content on the mechanical properties of epoxy composites. Strojniški Vestn 61:601-609 
12. Calebrese C, Hui L, Schadler LS, Nelson JK (2011) A review on the importance of nanocomposite processing to enhance electrical insulation. IEEE Trans Dielectr Electr Insul 18:938-945

13. Bell M, Krentz T, Nelson JK et al. (2017) Investigation of dielectric breakdown in silica-epoxy nanocomposites using designed interfaces. J Colloid Interface Sci 495:130-139

14. Caseri WR (2014) In situ synthesis of polymer-embedded nanostructures. In: Nicolais L, Catotenuto G (eds) Nanocomposites: in situ synthesis of polymer-embedded nanostructures. John Wiley and Sons, Hoboken, NJ, USA, p 45-72

15. Tanaka T, Kozako M, Fuse N, Ohki Y (2005) Proposal of a multicore model for polymer nanocomposite dielectrics. IEEE Trans Dielectr Electr Insul 12:669-681

16. Kurimoto M, Okubo H, Kato K et al. (2010) Permittivity characteristics of epoxy/alumina nanocomposite with high particle dispersibility by combining ultrasonic wave and centrifugal force. IEEE Trans Dielectr Electr Insul 17:1268-1275

17. Zou H, Wu S, Shen J (2008) Polymer/silica nanocomposites: preparation, characterization, properties, and applications. Chem Rev 108:3893-3957

18. Afzal A, Siddiqi HM (2011) A comprehensive study of the bicontinuous epoxy-silica hybrid polymers: I. Synthesis, characterization and glass transition. Polymer 52:1345-1355

19. Judeinstein P, Sanchez C (1996) Hybrid organic-inorganic materials: a land of multidisciplinarity. J Mater Chem 6:511-525

20. Matějka L, Pleštil J, Dušek K (1998) Structure evolution in epoxy-silica hybrids: sol-gel process. J Non Cryst Solids 226:114-121

21. Matějka L, Dušek K, Pleštil J et al. (1999) Formation and structure of the epoxy-silica hybrids. Polymer 40:171-181

22. Nazir T, Afzal A, Siddiqi HM et al. (2010) Thermally and mechanically superior hybrid epoxy-silica polymer films via solgel method. Prog Org Coatings 69:100-106

23. Yu W, Fu J, Dong X et al. (2013) Highly populated and nearly monodispersed nanosilica particles in an organic medium and their epoxy nanocomposites. ACS Appl Mater Interfaces 5:8897-8906

24. Beaucage G (1995) Approximations leading to a unified exponential/power-law approach to small-angle scattering. J Appl Crystallogr 28:717-728

25. Smith AL (1960) Infrared spectra-structure correlations for organosilicon compounds. Spectrochim Acta 16:87-105
26. González MG, Cabanelas JC, Baselga J (2012) Applications of FTIR on epoxy resins - identification, monitoring the curing process, phase separation and water uptake. In: Infrared spectroscopy - materials science, engineering and technology. InTech, Rijeka, Croatia, p 261-284

27. Rubio F, Rubio J, Oteo JL (1998) A FT-IR study of the hydrolysis of tetraethylorthosilicate (TEOS). Spectrosc Lett 31:199-219

28. Launer PJ, Arkles B (2013) Infrared analysis of organosilicon compounds: spectra-structure correlations. In: Arkles B, Larson GL (eds) Silicon compounds: silanes and silicones, 3rd edn. Gelest, Inc., Morrisville, PA, p 177-180

29. Arunkumar T, Ramachandran S (2017) Surface coating and characterisation of polyurea for liquid storage. Int $\mathrm{J}$ Ambient Energy 38:781-787

30. Perchacz M, Beneš H, Zhigunov A et al. (2016) Differentlycatalyzed silica-based precursors as functional additives for the epoxy-based hybrid materials. Polymer 99:434-446

31. Beaucage G (2012) Combined small-angle scattering for characterization of hierarchically structured polymer systems over nano-to-micron meter: part II theory. In: Matyjaszewski K, Möller M (eds) Polymer science: a comprehensive reference, vol 2. Elsevier B.V., Amsterdam, Netherlands, p 399-409

32. Capeletti LB, Baibich IM, Butler IS, Dos Santos JHZ (2014) Infrared and Raman spectroscopic characterization of some organic substituted hybrid silicas. Spectrochim Acta 133:619-625

33. Piscitelli F, Lavorgna M, Buonocore GG et al. (2013) Plasticizing and reinforcing features of siloxane domains in amine-cured epoxy/silica hybrids. Macromol Mater Eng 298:896-909

34. Ponyrko S, Kobera L, Brus J, Matějka L (2013) Epoxy-silica hybrids by nonaqueous sol-gel process. Polymer 54:6271-6282

35. Kuo S-W, Chang F-C (2011) POSS related polymer nanocomposites. Prog Polym Sci 36:1649-1696

36. Ayandele E, Sarkar B, Alexandridis P et al. (2012) Polyhedral oligomeric silsesquioxane (POSS)-containing polymer nanocomposites. Nanomaterials 2:445-475

37. Bauer BJ, Liu DW, Jackson CL, Barnes JD (1996) Epoxy/SiO2 interpenetrating polymer networks. Polym Adv Technol 7:333-339

38. Pochan JM, Gruber RJ, Pochan DF (1981) Dielectric relaxation phenomena in a series of polyhydroxyether copolymers of bisphenol-A-endcapped polyethylene glycol with epichlorohydrin. J Polym Sci Polym Phys Ed 19:143-149 